\title{
Proximal esophageal contraction after induction of ineffective distal contraction by sildenafil in healthy volunteers
}

\section{Tarciana Vieira Costa ${ }^{a}$, Roberto Oliveira Dantas ${ }^{b}$}

Ribeirão Preto Medical School, University of São Paulo SP, Brazil, Hospital Universitário Lauro Wanderley, Federal University of Paraíba, João Pessoa, PB, Brazil

Abstract

\section{Introduction}

In healthy subjects, liquid and solid swallows are followed by esophageal peristaltic contractions, a contracting process coordinated despite the neural control of different muscles in the proximal and distal esophagus [1-3]. Cervical esophagus

Department of Medicine, a Hospital Universitário Lauro Wanderley, Federal University of Paraíba, João Pessoa, PB (Tarciana Vieira Costa);

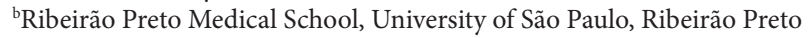
SP (Roberto Oliveira Dantas), Brazil

\section{Conflict of Interest: None}

Correspondence to: Roberto Oliveira Dantas, Department of Medicine, Ribeirão Preto Medical School - University of São Paulo, Av. Bandeirantes 3900 - Campus da USP, 14049-900 Ribeirão Preto, SP Brazil, e-mail: rodantas@fmrp.usp.br

Received 12 July 2019; accepted 11 November 2019; published online 29 November 2019

DOI: https://doi.org/10.20524/aog.2019.0443 is composed of striated muscle that is under the control of the central nervous system [2]. The striated muscle is progressively replaced by smooth muscle, predominant in the lower half of the organ. In thoracic esophagus muscle function is controlled by the myenteric plexus, whose effect increases from proximal to distal esophagus [1]. A peristaltic break is observed in the transition zone between the striated and smooth muscle, and is characterized by a decrease in the amplitude of the proximal contraction wave to below $30 \mathrm{mmHg}$ in the proximal border, and an increase in the distal contraction wave to above $30 \mathrm{mmHg}$ in the distal border [4].

It has been suggested that the esophagus has 2 separate contraction waves, one above and one below the proximal transition zone, properly coordinated during normal bolus transport [5]. Despite the possibility of independent contractions in the proximal and distal esophagus, we hypothesized that an induced impairment of distal esophageal contractions might affect contractions in the proximal esophagus.

Impairment of distal esophageal contractions was induced by sildenafil, a phosphodiesterase type 5 inhibitor that 
causes guanosine 3' 5' cyclic monophosphate accumulation and has been used for the treatment of hypercontractile esophagus [6-8]. Sildenafil can either cause smooth muscle relaxation or decrease its excitability, leading to decreased resting lower esophageal sphincter (LES) pressure and lower amplitude of distal peristaltic waves, with effects on esophageal smooth muscle but not on esophageal striated muscle [6]. The objective of this investigation was to evaluate changes in proximal esophageal contractions following the decrease of distal esophagus contractions induced by sildenafil.

\section{Patients and methods}

\section{Volunteers}

The esophageal motility of 10 men and 12 women aged from 22-50 years (mean: 38.1 years \pm standard deviation: 7.7 years) was evaluated. Mean body weight was $80.9 \pm 13.6 \mathrm{~kg}$, mean height $1.66 \pm 0.06 \mathrm{~m}$, and mean body mass index $29.1 \pm 3.7 \mathrm{~kg} / \mathrm{m}^{2}$. Volunteers did not have any gastroenterological, neurological or endocrine disease, previous surgery in the digestive tract or any disease at the time of esophageal motility evaluation. They did not complain of dysphagia, heartburn, acid regurgitation or chest pain. The investigation was approved by the Human Research Ethics Committee of the University Hospital of Ribeirão Preto (approval number 14757/2012) and all volunteers gave written informed consent to participate in the investigation.

\section{Esophageal motility}

Esophageal motility was assessed by high-resolution impedance/manometry, with a 32-channel solid state catheter and 16-channel impedance (InSIGHT High Resolution Impedance/Manometry System, Sandhill Instruments, Highlands Ranch, CO, USA). The catheter was calibrated at pressures 0 and $100 \mathrm{mmHg}$. After a 6-h fasting period, with the volunteers in the sitting position, the impedance/manometry catheter was introduced transnasally to the stomach, for registration of intraluminal pressures from the pharynx to the stomach.

\section{Methods}

After stabilization of the manometric device, each volunteer performed, in the sitting position, 10 swallows of $5 \mathrm{~mL}$ saline at room temperature, with an interval of at least $30 \mathrm{sec}$ between swallows. Each volunteer performed one swallow of each $5 \mathrm{~mL}$ bolus volume. Double swallows were not considered for analysis, and when they were detected the volunteer was asked to swallow the $5 \mathrm{~mL}$ bolus again. After $5 \mathrm{~min}$ of the wet swallows, the volunteers performed 10 swallows of small $\left(1 \mathrm{~cm}^{3}\right)$ pieces of bread, with an interval of at least $30 \mathrm{sec}$ between swallows. If the volunteers perceived that the bread bolus was not propelled through the esophagus during this interval, they were instructed to perform dry swallows before swallowing another piece of bread. Double swallows were discarded, and when they were detected the participant was asked to swallow another piece of bread.

After performing 10 wet swallows and 10 solid swallows, each volunteer received $50 \mathrm{mg}$ of oral sildenafil (Pfizer Inc., New York, NY, USA) diluted in $10 \mathrm{~mL}$ of water, giving a mean dose of $0.64 \pm 0.11 \mathrm{mg} / \mathrm{kg}$. Fifteen min after sildenafil ingestion, wet and solid bolus swallows were repeated in a random order.

\section{Measurements}

The manometric study consisted of an analysis of the integrated relaxation pressure (IRP) of the LES, distal contractile integral (DCI), proximal contraction length (PCL), proximal contractile integral (PCI), proximal contraction duration (PCD), and upper esophageal sphincter (UES) pressure. The methods used for the measurement of each of these variables have been described previously $[9,10]$. Proximal contraction was defined as contraction in the proximal border of the transition zone between striated and smooth muscle and distal contraction was defined as contraction in the distal border of the transition zone (Fig. 1) [4]. Ineffective contractions were defined as failed (DCI $<100 \mathrm{mmHg}$.sec.cm) or weak (DCI $>100$ mmHg.sec.cm but $<450$ mmHg.sec.cm) contractions, following the Chicago classification v3.0 [10]. PCL was defined as the length of the proximal contraction from the lower border of the UES until the peristaltic break, where the amplitude of contraction declined below $20 \mathrm{mmHg}$. PCI was calculated as the amplitude of proximal contraction $\times$ PCD $\times$ length of proximal contraction with amplitude above $20 \mathrm{mmHg}$. PCD was the duration of the contraction above $20 \mathrm{mmHg}$, measured in the proximal esophagus. The UES pressure was measured in the UES channels in a time window of $10 \mathrm{sec}$ before and

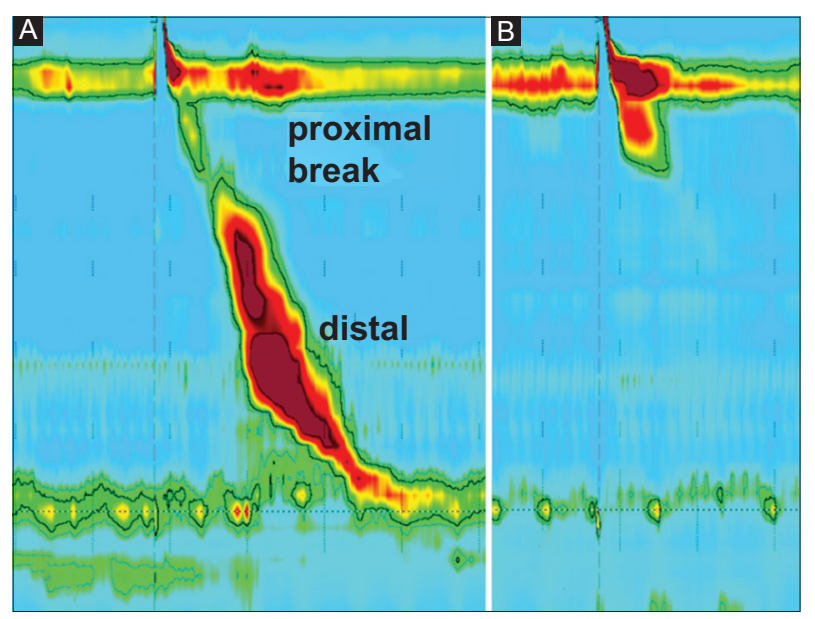

Figure 1 High resolution manometry of swallows of liquid bolus in healthy volunteer before (A) and after (B) sildenafil. The effect of sildenafil on esophageal motility is seen in proximal (above) and distal (below) peristaltic break 
after sildenafil intake, after liquid and solid swallows. The UES pressure was considered the highest pressure measured.

Bolus transit was assessed by impedance with wet swallows only. Complete and incomplete esophageal bolus transit were evaluated using the Sandhill High Resolution Impedance/ Manometry System. Complete bolus transit through the esophagus was established when, after a drop of more than 50\% from baseline, impedance values returned to more than $50 \%$ of baseline values within $20 \mathrm{sec}$, whereas incomplete transit was determined when, after saline intake, impedance dropped more than $50 \%$ from baseline but did not return to more than $50 \%$ of baseline values within $20 \mathrm{sec}$.

\section{Statistical analysis}

Data were tested for normality using the Shapiro-Wilk test. Comparisons between measurements before and after sildenafil intake were made using a 2-tailed Student's $t$ test for normally distributed data and the Mann-Whitney $U$ test for data without normal distribution. Results are shown as mean \pm standard deviation or mean and standard error.

\section{Results}

Sildenafil caused an increase in the proportion of ineffective distal contractions from $24.8 \%$ to $68.8 \%$ of wet swallows, and from $43.4 \%$ to $82.2 \%$ of solid swallows. With liquid and solid boluses sildenafil caused a significant reduction in LES IRP and in DCI (Fig. 2), and a significant increase in PCL, PCI and PCD, with a reduction in UES pressure following solid bolus ingestion (Table 1). After liquid bolus ingestion the UES pressure did not change.

Before sildenafil intake, ineffective distal contractions were associated with a decrease in PCL with wet swallows, and with decreased PCL and PCI with solid swallows, compared with

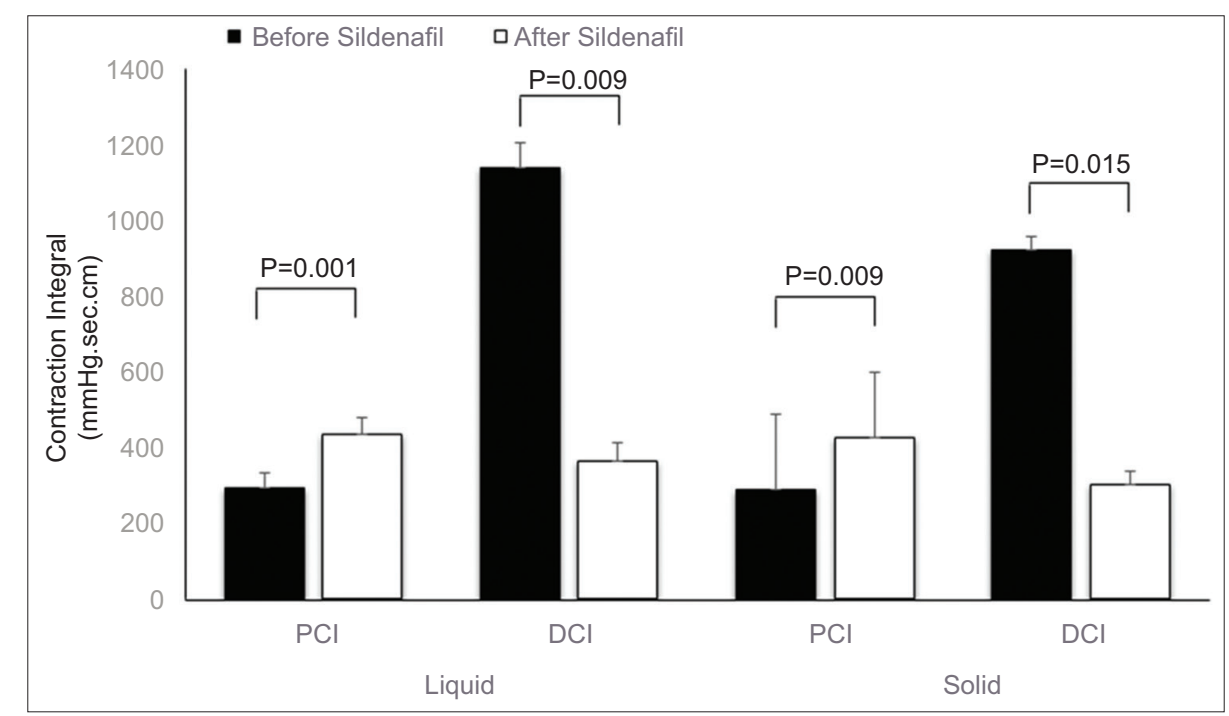

Figure 2 Proximal contractile integral (PCI) and distal contraction integral (DCI) before and after sildenafil intake, after swallows of liquid and solid bolus (mean and SEM)

Table 1 Esophageal contractions before and after sildenafil in healthy subjects after swallows of liquid or solid bolus.

\begin{tabular}{|c|c|c|c|c|c|c|}
\hline \multirow[t]{2}{*}{ Variables } & \multicolumn{3}{|c|}{ Liquid bolus } & \multicolumn{3}{|c|}{ Solid bolus } \\
\hline & Before & After & $\mathrm{P}$-value & Before & After & P-value \\
\hline IRP (mmHg) & $7.3 \pm 4.5$ & $4.6 \pm 3.1$ & $0.001^{*}$ & $8.6 \pm 4.1$ & $4.7 \pm 2.6$ & 0.001 \\
\hline DCI (mmHg.sec.cm) & $1140.0 \pm 936.4$ & $362.9 \pm 161.2$ & $0.009^{*}$ & $924.4 \pm 815.1$ & $303.2 \pm 166.1$ & 0.015 \\
\hline PCL $(\mathrm{cm})$ & $4.6 \pm 1.1$ & $5.0 \pm 1.1$ & $0.018^{*}$ & $3.8 \pm 1.1$ & $4.6 \pm 1.1$ & 0.002 \\
\hline PCI (mmHg.sec.cm) & $293.8 \pm 194.2$ & $436.1 \pm 308.2$ & $0.001^{*}$ & $287.7 \pm 205.9$ & $427.6 \pm 242.8$ & 0.009 \\
\hline $\mathrm{PCD}(\mathrm{sec})$ & $2.4 \pm 0.8$ & $2.7 \pm 0.9$ & $0.004^{*}$ & $2.2 \pm 0.7$ & $2.6 \pm 1.0$ & 0.039 \\
\hline UES pressure (mmHg) & $469.4 \pm 85.9$ & $447.5 \pm 92.6$ & 0.123 & $475.9 \pm 102.6$ & $425.8 \pm 75.7$ & 0.001 \\
\hline
\end{tabular}

Values are mean $\pm \mathrm{SD}$

IRP, integrated relaxation pressure; DCI, distal contraction integral; $P C L$, proximal contractile length; PCI, proximal contractile integral; $P C D$, proximal contraction duration; UES, upper esophageal sphincter 
Table 2 Proximal esophageal contractions before and after sildenafil with swallows of liquid and solid bolus followed by normal or ineffective contractions in distal esophagus

\begin{tabular}{|c|c|c|c|c|c|c|}
\hline \multirow[t]{2}{*}{ Variables } & \multicolumn{3}{|c|}{ Before sildenafil } & \multicolumn{3}{|c|}{ After sildenafil } \\
\hline & Normal & Ineffective & P-value & Normal & Ineffective & $\mathrm{P}$-value \\
\hline \multicolumn{7}{|l|}{ Liquid } \\
\hline PCL $(\mathrm{cm})$ & $4.7 \pm 1.4$ & $4.1 \pm 1.4$ & $0.010^{*}$ & $4.6 \pm 1.3$ & $5.3 \pm 1.3$ & 0.001 \\
\hline PCI (mmHg.sec.cm) & $300.6 \pm 252.8$ & $262.7 \pm 220.1$ & 0.359 & $254.5 \pm 164.9$ & $528.5 \pm 368.6$ & 0.001 \\
\hline UES pressure (mmHg) & $465.0 \pm 109.7$ & $478.7 \pm 108.6$ & 0.255 & $390.9 \pm 83.4$ & $475.4 \pm 104.2$ & 0.001 \\
\hline \multicolumn{7}{|l|}{ Solid } \\
\hline PCL $(\mathrm{cm})$ & $4.3 \pm 1.3$ & $3.2 \pm 1.1$ & $0.001^{*}$ & $4.4 \pm 1.3$ & $4.8 \pm 1.2$ & 0.093 \\
\hline PCI (mmHg.sec.cm) & $356.7 \pm 250.0$ & $168.7 \pm 128.8$ & $0.001^{\star}$ & $306.9 \pm 177.3$ & $486.9 \pm 293.9$ & 0.001 \\
\hline PCD (sec) & $2.6 \pm 0.9$ & $1.7(0.6)$ & 0.239 & $2.4 \pm 0.8$ & $2.8 \pm 1.3$ & 0.060 \\
\hline UES pressure (mmHg) & $481.2 \pm 120.4$ & $479.3 \pm 98.1$ & 0.660 & $392.5 \pm 81.2$ & $435.7 \pm 89.5$ & 0.007 \\
\hline
\end{tabular}

Values are mean \pm SD

PCL, proximal contraction length; PCI, proximal contractile integral; PCD, proximal contraction duration; UES, upper esophageal sphincter

Table 3 Proximal esophageal contractions before and after sildenafil with swallows of liquid bolus followed by complete or incomplete bolus transit. Mean (SD)

\begin{tabular}{|c|c|c|c|c|c|c|}
\hline \multirow[t]{2}{*}{ Variables } & \multicolumn{3}{|c|}{ Before sildenafil } & \multicolumn{3}{|c|}{ After sildenafil } \\
\hline & Complete & Incomplete & P-value & Complete & Incomplete & P-value \\
\hline PCL $(\mathrm{cm})$ & $4.7 \pm 1.4$ & $4.6 \pm 1.3$ & 0.337 & $4.8 \pm 1.0$ & $5.3 \pm 1.3$ & 0.020 \\
\hline PCI (mmHg.sec.cm) & $310.5 \pm 253.1$ & $291.7 \pm 240.2$ & 0.491 & $384.2 \pm 264.1$ & $482.4 \pm 364.7$ & 0.038 \\
\hline $\mathrm{PCD}(\mathrm{sec})$ & $2.5 \pm 2.5$ & $2.4 \pm 2.4$ & 0.351 & $2.7 \pm 0.7$ & $2.8 \pm 1.2$ & 0.526 \\
\hline UES pressure $(\mathrm{mmHg})$ & $472.4 \pm 103.7$ & $476.6 \pm 110.7$ & 0.369 & $456.3 \pm 101.8$ & $453.5 \pm 102.5$ & 0.860 \\
\hline
\end{tabular}

Values are mean \pm SD

PCL, proximal contraction length; PCI, proximal contractile integral; PCD, proximal contraction duration; UES, upper esophageal sphincter

normal distal contractions. After sildenafil, ineffective distal contractions with liquid and solid boluses were associated with increased PCL, PCI, PCD, and UES pressure (Table 2). There was no difference in PCI before and after sildenafil when distal contractions had normal amplitude, for liquid and solid boluses. However, for ineffective distal contractions, the PCI was higher after sildenafil intake than before (Fig. 3).

Before the ingestion of sildenafil the PCL, PCI, PCD, and UES pressure did not differ between swallows followed by complete or incomplete liquid bolus transit (Table 3). However, after sildenafil, there was an increase of PCL and PCI after swallows with incomplete bolus transit, compared with swallows followed by complete bolus transit. There was no adverse event after administration of sildenafil.

\section{Discussion}

Sildenafil causes changes in distal esophageal motility [11]. In this investigation we observed a decrease in LES IRP and DCI for liquid and solid boluses. The changes in distal esophagus were associated with changes in proximal esophagus, such as increase in PCL, PCI, and PCD for liquid and solid bolus. With solid bolus, there was also a decrease in UES pressure. Motility

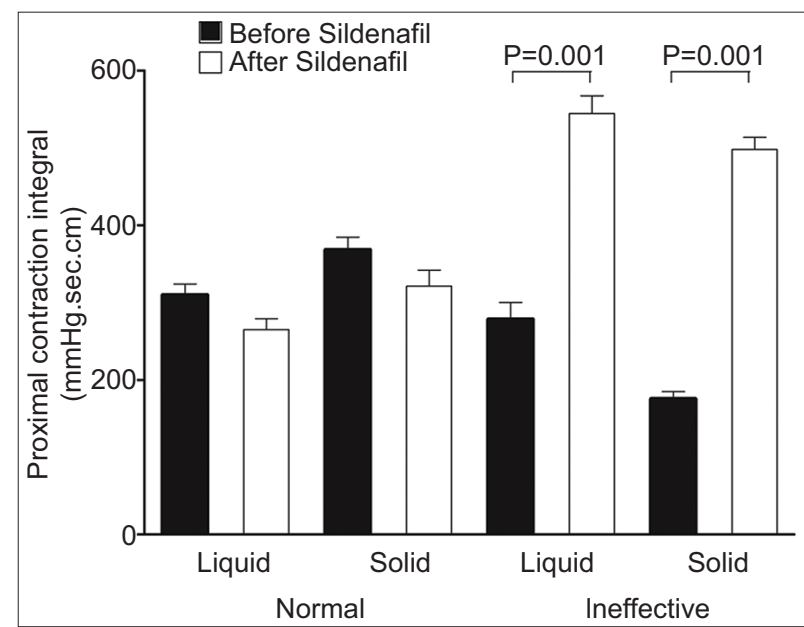

Figure 3 Proximal contractile integral after normal or ineffective distal contractions, before and after sildenafil intake, with swallows of liquid and solid bolus (mean and standard error of mean)

changes were almost the same for liquid and solid bolus. Changes in proximal motility suggest that there is compensation in proximal esophagus as a consequence of impaired distal motility. This compensation could be triggered by bolus inside the esophagus, when both esophageal sensitivity and the 
central control of swallowing are unchanged. The alteration in contraction was not a direct effect of sildenafil on proximal esophagus, because normal contractions after sildenafil did not differ from normal contractions before sildenafil.

Ineffective contractions in distal esophagus before sildenafil intake resulted in a shorter PCL with liquid and solid bolus, and a decrease in PCI with solid bolus. This suggests that spontaneous hypotensive contraction may be a consequence of the swallowing center action [3], with a decrease in proximal and distal esophageal function. When distal hypotensive contractions were induced by sildenafil, proximal contractions increased in intensity, indicating adaptation to the altered distal esophageal motility. The alteration in proximal contractions included the UES, which has a decrease in pressure with sildenafil, but an increase in pressure with ineffective contraction compared with swallows followed by normal contraction, which could be a response to avoid bolus reflux through the UES [12].

A multitude of factors may be involved in the occurrence of ineffective contractions [13]. The striated muscle in proximal esophagus is controlled by the central nervous system, and the presence of the bolus inside the esophagus triggers the onset of the esophageal phase of swallowing [2]. The propagation of the contraction wave from proximal esophagus slows down, become weaker, and dies at the proximal end of the esophageal transition zone. Another contraction wave is born distally, due to the presence of the myenteric plexus in that segment, responsible for transporting bolus into the smooth-muscle predominant lower esophagus [5]. These 2 contractions are properly coordinated for normal bolus transport [5]. Bolus swallowing activates vagal sensory neurons and evokes peristalsis via vagal dorsal motor neurons connected to the smooth muscle. Incorrect or insufficient information supplied to the solitary nucleus may result in impaired swallowing. The nucleus ambiguus acts as a center that controls striated muscle contractions [13]. The proximal esophageal response associated with the distal contraction impairment may be an esophageal adaptation to avoid difficulties in esophageal bolus transit and dysphagia.

Changes in proximal esophageal contraction with sildenafil may explain, at least in part, the non-influence of ineffective distal esophageal contraction induced by sildenafil on saliva transport through the esophagus [14]. The increase in proximal esophageal contraction, and perhaps the pharyngeal pump [15], which has been suggested as responsible for efficient saliva transport through the esophagus [14], may compensate for the absence of distal contraction. This compensation is corroborated by the fact that sildenafil has no effect on esophageal sensitivity and causes a prolongation in esophageal bolus clearance in the distal smooth-muscle esophageal segment [11].

Previous investigations did not find any alteration of proximal esophageal contractions after induction of ineffective distal contractions by sildenafil [11]. There are important differences from the actual investigation. The manometric evaluation was performed in a supine position with a 9-channel solid state probe, and the proximal measurement was made at $20 \mathrm{~cm}$ from the LES [11], and not in the entire proximal segment.

The alterations in distal esophageal motility caused by sildenafil were similar to those seen in patients with systemic sclerosis [16,17]; however, in this latter condition the proximal esophageal contractions do not have increased amplitude [16,18] or increased PCI [16]. Patients with the disease show a presence and severity of esophageal symptoms (dysphagia, heartburn and regurgitation) that may not reflect the intensity of the alterations in esophageal motility [19]. In achalasia, a disease that causes loss of the esophageal myenteric plexus $[20,21]$ and ineffective contractions in distal esophagus, there is no association with an increase in proximal contraction [20-22], perhaps because of the loss of esophageal sensitivity [23,24]. These results suggest that the proximal esophageal response to the decrease of distal contraction is mediated by esophageal sensitivity. As previously demonstrated, solid bolus swallow caused more ineffective contractions than liquid bolus [25].

This investigation had some limitations. First, the volunteers were evaluated only in the sitting position, which would cause a lower IRP and DCI [26]; second, the effect of sildenafil after liquid and solid bolus swallowing was not evaluated at the same time after ingestion. However, the effect of the drug on the contraction amplitude and LES pressure of healthy volunteers persists for at least $30 \mathrm{~min}[6,11]$.

In conclusion, induction of distal ineffective motility by sildenafil causes an increase in proximal esophageal motility, suggesting an adaptive compensation of the proximal esophagus for the effect of sildenafil on distal esophageal motility.

\section{Summary Box}

\section{What is already known:}

- Sildenafil causes ineffective motility in the distal esophageal body

- This effect is not seen in the proximal esophageal body

- The ineffective distal motility does not cause an alteration of saliva transit through the esophagus

\section{What the new findings are:}

- In distal esophagus sildenafil caused a significant reduction in distal contractile integral and in lower esophageal sphincter integrated relaxation pressure

- Spontaneous distal hypotensive esophageal motility, not induced by sildenafil, was associated with a decrease in proximal esophageal motility

- Induction of distal hypotensive esophageal motility by sildenafil caused an increase in proximal esophageal motility

- Proximal esophagus adapted to an induced impairment of distal esophageal motility 


\section{References}

1. Goyal RK, Chaudhury A. Physiology of normal esophageal motility. J Clin Gastroenterol 2008;42:610-619.

2. Lang IM. Brain stem control of the phases of swallowing. Dysphagia 2009;24:333-348.

3. Shaw SM, Martino R. The normal swallow. Muscular and neurophysiological control. Otolaryngol Clin North Am 2013;46:937-956.

4. Pohl D, Ribolsi M, Savarino E, et al. Characteristics of the esophageal low-pressure zone in healthy volunteers and patients with esophageal symptoms: assessment by high-resolution manometry. Am J Gastroenterol 2008;103:2544-2549.

5. Li M, Brasseur JG, Dodds WJ. Analyses of normal and abnormal esophageal transport using computer simulations. Am J Physiol 1994;266:G525-G543.

6. Lee JI, Park H, Kim JH, Lee SI, Conklin JL. The effect of sildenafil on oesophageal motor function in healthy subjects and patients with nutcracker oesophagus. Neurogastroenterol Motil 2003;15:617-623.

7. Hong YS, Min YW, Rhee PL. Two distinct types of hypercontractile esophagus: classic and spastic jackhammer. Gut Liver 2016;10:859-863.

8. Roman S, Kahrilas PJ. Distal esophageal spasm. Dysphagia 2012;27:115-123.

9. Herregods TV, Roman S, Kahrilas PJ, Smout AJ, Bredenoord AJ. Normative values in esophageal high-resolution manometry. Neurogastroenterol Motil 2015;27:175-187.

10. Kahrilas PJ, Bredenoord AJ, Fox M, et al; International High Resolution Manometry Working Group. The Chicago Classification of esophageal motility disorders, v3.0. Neurogastroenterol Motil 2015;27:160-174.

11. Kim HS, Conklin JL, Park H. The effect of sildenafil on segmental oesophageal motility and gastro-oesophageal reflux. Aliment Pharmacol Ther 2006;24:1029-1036.

12. Blais P, Patel A, Sayuk GS, Gyawali CP. Upper esophageal sphincter (UES) metrics on high-resolution manometry (HRM) differentiate achalasia subtypes. Neurogastroenterol Motil 2017;29.

13. Chen JH. Ineffective esophageal motility and the vagus: current challenges and future prospects. Clin Exp Gastroenterol 2016;9:291-299.

14. Dantas RO, Oliveira RB, Aprile LR, Hara SH, Sifrim DA. Saliva transport to the distal esophagus. Scand J Gastroenterol
2005;40:1010-1016.

15. Buthpitiya AG, Stroud D, Russell CO. Pharyngeal pump and esophageal transit. Dig Dis Sci 1987;32:1244-1248.

16. Roman S, Hot A, Fabien N, et al; Réseau Sclérodermie des Hospices Civils de Lyon. Esophageal dysmotility associated with systemic sclerosis: a high-resolution manometry study. Dis Esophagus 2011;24:299-304.

17. Denaxas K, Ladas SD, Karamanolis GP. Evaluation and management of esophageal manifestations in systemic sclerosis. Ann Gastroenterol 2018;31:165-170.

18. Dantas RO, Aprile LRO. Proximal esophageal muscle contractions in patients with nutcracker esophagus and patients with systemic sclerosis. J Brasil Gastroenterol 2002;2:110-114.

19. Raja J, Ng C, Sujau I, Chin K, Sockalingam S. High-resolution oesophageal manometry and 24-hour impedance-pH study in systemic sclerosis patients: association with clinical features, symptoms and severity. Clin Exp Rheumatol 2016:34(Suppl 100):115-121.

20. Dantas RO, Aprile LR, Aben-Athar CG, Miranda AL. Esophageal striated muscle contractions in patients with Chagas' disease and idiopathic achalasia. Braz J Med Biol Res 2002;35:677-683.

21. Dunaway PM, Maydonovitch CL, Wong RK. Characterization of esophageal striated muscle in patients with achalasia. Dig Dis Sci 2000;45:285-288.

22. Dantas RO, Aprile LRO. Proximal and distal esophageal contractions in patients with vigorous or classic esophageal Chagas' disease. Arq Gastroenterol 2005;42:9-12.

23. Ejima FH, Dantas RO, Simões MV, Marin Neto JA, Meneghelli UG. Intraesophageal balloon distension test in Chagas' disease patients with noncardiac chest pain. Dig Dis Sci 1998;43:2567-2571.

24. Paterson WG. Esophageal and lower esophageal sphincter response to balloon distention in patients with achalasia. Dig Dis Sci 1997;42:106-112.

25. Xiang X, Wang A, Tu L, et al. The differences in the esophageal motility between liquid and solid bolus swallows: A multicenter high-resolution manometry study in Chinese asymptomatic volunteers. Neurogastroenterol Motil 2019;31:e13574.

26. Zhang X, Xiang X, Tu L, Xie X, Hou X. Esophageal motility in the supine and upright positions for liquid and solid swallows through high-resolution manometry. J Neurogastroenterol Motil 2013;19:467-472. 